\title{
SELECTION OF AN APPROPRIATE DISTRIBUTION CHANNEL FOR HIGH- VALUE STONE
}

\author{
Nikoleta Mikušová', Eva Tomková', David Hrdlý ${ }^{2}$ Petr Průša², Rudolf Kampf ${ }^{3}$
}

${ }^{1}$ Faculty of Mining, Ecology, Process Control and Geotechnology, Technical University of Košice, Letná 9, 042 00 Košice, Slovakia, e-mail: nikoleta.mikusova@tuke.sk, eva.tomkova@tuke.sk

2 Department of Transport management, marketing and logistics. Jan Perner Transport Faculty, University of Pardubice, Pardubice, Czech Republic, e-mail: hrdy.david@gmail.com, petr.prusa@upce.cz,

3 The Institute of Technology and Business in Ceske Budejovice, Okruzni 517/10, 37001 Ceske Budejovice, Czech Republic, e-mail: kampf@mail.vstecb.cz

Received: 2018.04.21

Accepted: 2018.05.20

Published: 2018.06.01

\begin{abstract}
Selection of distribution channel type is an important decision of every manufacturing company and also for production engineering. Appropriate choice of distribution channel can save considerable costs while maintaining a high level of customer service. Determination of an appropriate strategy for the management of enterprise distribution channel. In this article, the selection of the type of distribution channel is proposed using ANP method to determine the strength of influence of input factors on the target set of potential options. Submitted model is very clear, understandable and according to the proposed methodology easy to implement, while also providing clear and understandable results during the selection of the type of distribution channel. The proposed model is primarily targeting for distribution of high-value stone which needs to decide which distribution strategy should be chosen or if to switch to another distribution strategy more suitable for the company needs.
\end{abstract}

Keywords: distribution, channel, model.

\section{INTRODUCTION}

From the perspective of Multiple Criteria Decision-Analysis (MCDM), there is a wide range of methods used for dealing with choice of not only the type of distribution channel. MCDM history goes back about 40 years ago, with Alias, et al. [2] reviewed over 70 of these techniques. Aruldoss M. et. al. [3], for example, compiled the inventory of multi-criterial methods with examples of their application. A plethora of studies uses MDCM to select and evaluate a supplier. Ho, W. et. al. [7, 8] and Agarwal, et. al. [1] prepared a summary of MCDM techniques and their use in choosing a supplier evaluation (Table 1).

Singh, A., and Malik, SK [26] divided MCDM in their work into two categories: Multi-Attribute
Decision Making (MADM) and Multi-Objective Decision Making (MODM). MADM focuses on the selection of the best alternative from the set of pre-defined alternatives where the set is limited by a number of input factors [20]. One of the recent studies (by [4]) seeks to raise awareness about the methodology of Multiple-attribute of Decision Making (MADM) in connection with Enterprise Resource Planning (ERP) projects. MODM, on the other hand, focuses on the design alternatives on the basis of the input factors [15]. The possibilities are usually endless and the aim is to choose the possibility that best fits the constraints and priorities set by the decision maker.

The basis for the decision making in MCDM is Saaty's approach [22], which builds on a large number of studies. Sha, DY, \& Che, ZH [25] used 
Table 1. Review of MCDM techniques in the scientific literature

\begin{tabular}{|c|c|c|}
\hline & Technique & Authors \\
\hline \multirow{2}{*}{$\frac{0}{\tilde{0}}$} & Data Envelopment Analysis (DEA) & Liu et al. (2000); Narasimhan et al. (2001); Talluri and Sarkis (2002); Sedel \\
(2006); Saen (2007)
\end{tabular}

the AHP method to design a distribution chain network, where the focus was on the selection of a suitable partner, planning, distribution, and manufacturing. Kahraman, C., Cebeci, U., \& Ulukan, Z. [12] dealt with a supplier selection using MCDM approach with help of the so-called Fuzzy AHP method.

The MCDM approach has appeared in a number of studies focused on distribution logistics. Mallen B. [16] used this approach to select the distribution channel, where was this selection subdivided into several stages. W. Ho and A. Emrouznejad [7] used a combination of AHP methods and logical operators SAS / OR for structural design of a distribution grid. G. Nilay Serbest and Vayvay O. [17] proposed a model for selecting the most appropriate distribution channel using fuzzy AHP method.

\section{PROBLEM DEFINITION}

Only very few manufacturers sell their goods directly to the final consumer. Between the producer and the final consumer, there is a number of intermediaries, which make up the distribution chain. Distribution chain then can be understood as "part of the logistics chain that begins when the product leaves the company and ends at the final customer". K.D. Zylstra [28] defined the objective of distribution chain as an overcoming of the time, space and property inconsistencies in the course of the movement of goods and services to customers. The structure of the distribution chain is determined by functions/activities that each organization in the chain carries out. From the discussed company's perspective, which is the posi- tion of the manufacturer, its aim is to optimize distribution logistics for the customer. The aim is to design and build a suitable model for selecting the distribution chain, which will help the company reduce losses in the distribution part of the logistics chain. The discussed company currently uses the local branches in the Czech and Slovak Republic. The given model should provide an answer as to whether this is desirable or recommend switching to another type of distribution channel.

Distribution chains are formed as a network of vertically aligned companies, without any fixed structure. The specific structure largely depends on the nature of the distributed product and nature of the target market of the company. Even for companies producing similar products the "best" structure of the distribution chain cannot be unambiguously determined [6]. This should be created in relation to the overall business and marketing objectives of the company. The distribution chains thus differ in their length and width. Length is the number of distribution levels between the manufacturer and the customer. The width is given by the number of participants involved in the distribution at given level.

The distribution system must be therefore regularly inspected and modified by the manufacturer. Modification of distribution channels is essential if they do not function as planned, or if the way customers shop changed, the market expanded, new competition appeared, new ways of distribution are created or product moves to the next stage of its life cycle [29]. No distribution channel remains competitive throughout the product's whole life cycle [21]. The first potential customers may be willing to pay the price for a big cus- 


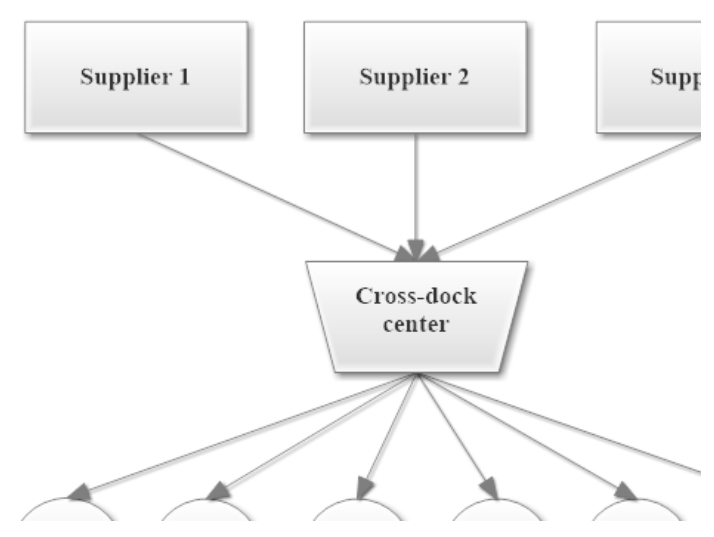

Fig. 1. Direct distribution

tomer added-value, but other potential customers will move to cheaper distribution routes.

\section{LOGICAL FRAMEWORK OF THE PROPOSED MODEL}

The proposed model is based on the goal definition of the proposed study because of both maximization and minimization factors, and also include the dependencies between these factors [13]. To create the model all alternatives must be related to all limiting factors. As already mentioned, the creation of a model for the choice of distribution channel must take into account both the company's perspective (minimization of cost factors) and the customer's perspective (maximization of customer service factors). Alternatives - A high importance is apparent when selecting a suitable distribution model for the given company. Distribution costs vary with the use of different types of distribution channels and it is at the discretion of company management to state

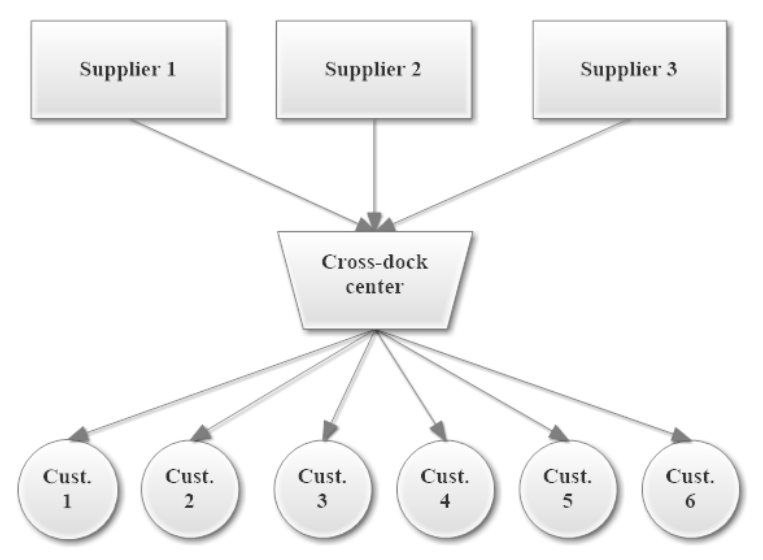

Fig. 2. Cross-dock center

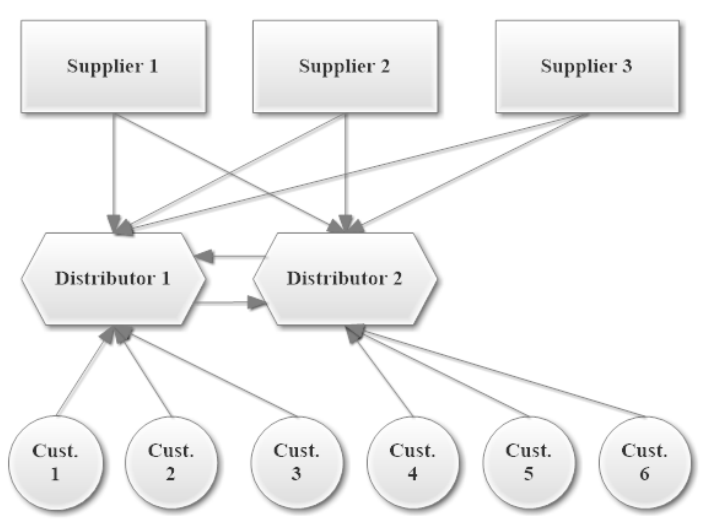

Fig. 3. Local branches or warehouses

its goal. For the proposed model four basic types of distribution channels were identified:

- Direct distribution - Products are stored in a central warehouse, or directly at the manufacturer, without the use of distribution centers in the distribution chain. Orders are processed directly and manufacturer delivers the order directly to the customer (Figure 1).

- Cross-dock center - goods are assembled, merged, or tailored to customer requirements only after the production in the cross-dock center with added value. The customer receives the all his orders in one package (Figure 2).

- Local branches or warehouses/distribution centers - local branches cover the market in order to achieve a strategic position for the customer (Figure 3).

- Offtake by the customer - storage is provided in warehouses, or directly at the manufacturer (also in local offices), with the difference that the picking up of the goods is directed by the customer (Figure 4).

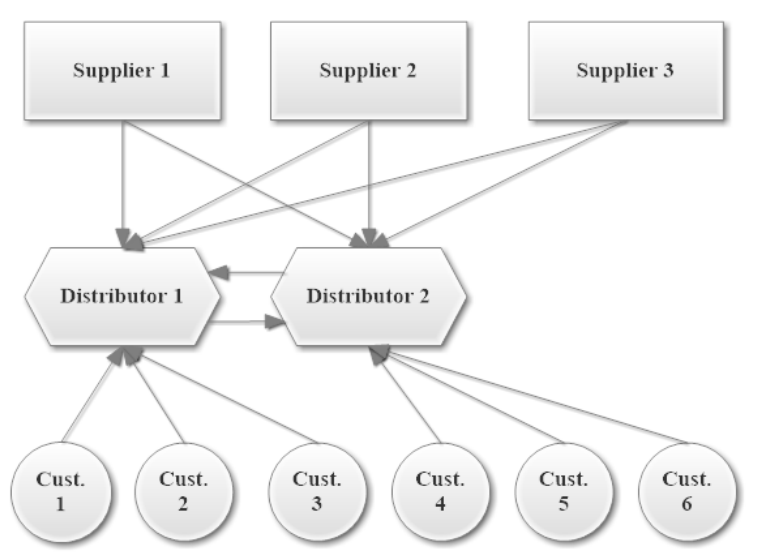

Fig. 4. Offtake by the customer 
Selected factors of customer service - From the customer's perspective, it is important to maximize customer service. Costantino, F., Di Graviá, G. [5] determined the factors of customer service, affecting the production rate of individual types of distribution channels. Adjusted factors used for the proposed model are:

- Product Availability - period determining how available the demanded product is in the distribution chain, it is a unit of time, it is the goal is to maximize system availability.

- Customer satisfaction - a factor tracking customer's satisfaction with a type of the distribution chain. It is obtained by querying about customer's experience, it is the goal is to achieve maximum customer satisfaction.

- Consolidation of orders - not all types of distribution chains are suitable for merging orders, the goal is to merge multiple potential orders so that the customer receives only one complete order.

- Order tracking - an important factor guaranteeing the possibility of accurate tracking of orders throughout the whole order process.

- Reliability of supply - the percent accuracy of ordered goods delivery.

- The speed of delivery - or also the distribution chain performance, measuring the speed of delivery of orders.

- Reverse logistics - the difficulty of reverse logistics for different types of distribution channels.

Selected cost criteria - Perspective of the company is limited by cost factors [5]. Revised factors are:
- Information - in the distribution chain everything has to be properly monitored, planned and kept in records. This obviously results in rising of costs for each different distribution channels.

- Storage - every distribution channel retains a certain quantity of goods, which raises the cost of storage, handling, transportation within the warehouse etc. Expenses again depend on a type of distribution channel.

- Operational - covers all expenses related to the management and administration of the given type of distribution channel. More complex distribution channel arrangement results in higher operating costs.

- Boot - the initial costs of implementing a new type of distribution channel, or the cost of switching to this channel from another type of distribution channel.

- Transport - traffic volume in the transport chain. Cost factor with big influences on the final results of cost criteria.

\section{PROPOSED MODEL}

To achieve the best possible results in the choice of the type of grid a two-phase model was designed. The model uses a modified version of Delphi method and a method of ANP, which provides partial results subsequently used in the TOPSIS method. The process of the proposed model is shown in Figure 5.

Delphi method - The first and most important step of the proposed model is a pairwise comparison of input factors and their influence on the resulting type of distribution routes. For this pur-

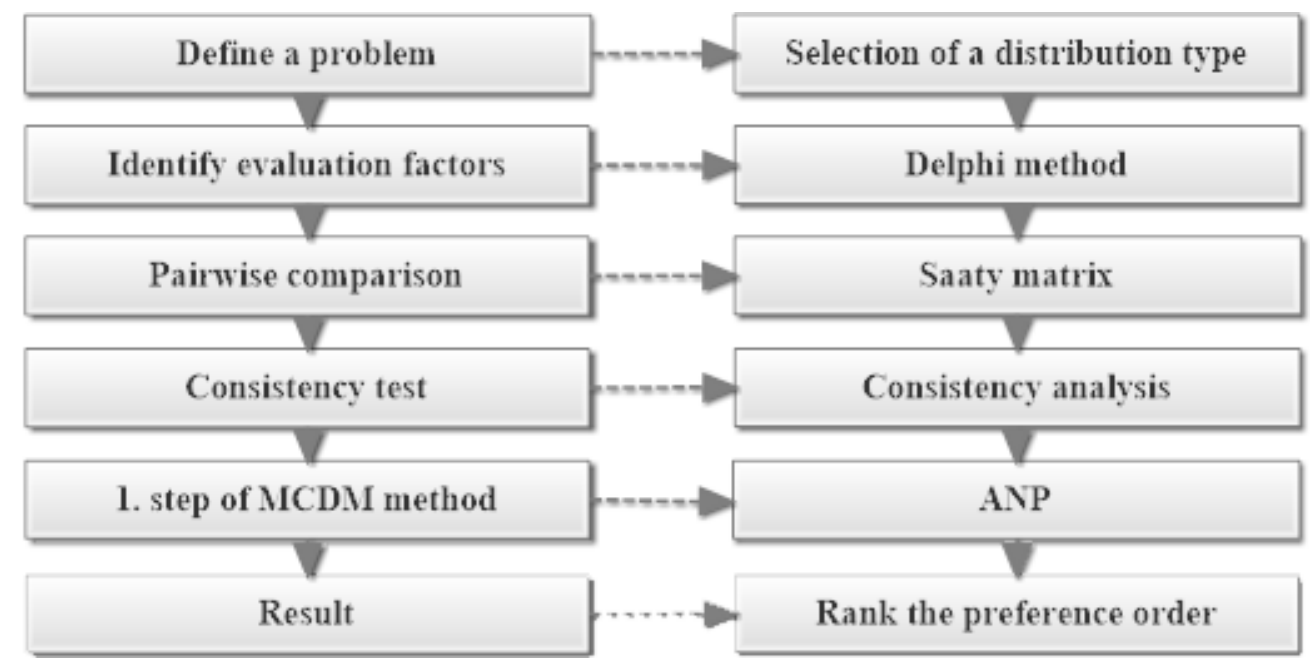

Fig. 5. Proposed model 
pose, there is an assembled group of evaluators, consisting of logistics managers, researchers, but also professionals, in order to achieve a correct evaluation of these factors possible. For this purpose, the proposed method is Delphi [14] which is suitable for the determination of a professional estimate by a selected group of people. It's a technique that uses subjective opinions of members of the expert group in order to obtain overall consensus views. Delphi method can be simply seen as a kind of brainstorming session with clear rules.

Saaty method - To obtain the weighting of individual factors a use of Saaty method is recommended [22]. The input to this method is the pairwise comparison of individual factors obtained in Step I. Each expert group is also assigned a weight, which represents the degree of influence on the resulting model. This method takes into account different preferences between criteria and a wide range scoring scale, which is intended for evaluation (Formula 1). Therefore, it is possible to detect even slight differences in preferences between the selected criteria, using the process of determining weight:

$$
\left(s_{i j}\right)=\left\{\begin{array}{l}
1-i \text { and } j \text { are equals; } \\
3-i \text { is slightly favour over } j \\
5-i \text { is strongly favour over } j \\
7-i \text { is very strongly favour over } j ; \\
9-i \text { is absolutely favour over } j
\end{array}\right.
$$

Values of 2, 4, 6, 8 are designed for evaluation of so-called interphase. This method compares each pair of criteria $i$ and $j$. Their evaluations are entered in the Saaty matrix (Formula 2), according to the following rules:

$$
S=\left(\begin{array}{cccc}
1 & s_{12} & \ldots & s_{1 k} \\
1 / s_{12} & 1 & \ldots & s_{2 k} \\
\vdots & \vdots & \ddots & \vdots \\
1 / s_{1 k} & 1 / s_{2 k} & \ldots & 1
\end{array}\right)
$$

This method is comprised of five steps [22], which include weight calculation $v_{i}$ by using the standardized geometric mean of Saaty matrix's rows:

Consistency analysis - An important factor to whom it is necessary to pay attention during pairwise comparison is consistency [22]. In case that we do not only transfer the exact measure- ments to elemental scale but use judgment, there is almost always inconsistency. (If we say that a is 3 times greater than $b$, but only $1 / 5$ times as good as c, c would have to be 15-times better than b to avoid inconsistency.) Given the characteristics of reciprocal matrices and eigenvalues, the minor inconsistency does not have any effect in determining the vector priorities.

The degree of consistency below the 0.10 $(10 \%)$ value is considered acceptable [9]. For higher values the pairwise comparison matrix should be adjusted, otherwise, the results of the entire model quickly lose their predictive value. Experimentally derived RI values reported by Saaty (1980) for a matrix of order 1-15 are shown in Table 2.

AHP / ANP method (Analytic Hierarchy Proces / Analytic Network Process) - Method of AHP [22, 23], which is widely discussed in literature $[10,18,27]$ is a method for priority setting which derives the relative priority based on pairwise comparisons of elements at the same hierarchical level using the absolute numbers at range from 1 to 9. Analytic Hierarchy Process (AHP) is a method that is appropriate for the hierarchical structure of the systems. Absolute numbers of the scale are approximations of weights ratio $\mathrm{w}_{\mathrm{j}} / \mathrm{w}_{\mathrm{k}}$ which make it possible to deduce the weights of $\mathrm{w}_{\mathrm{j}}$ a $\mathrm{w}_{\mathrm{k}}$. AHP method uses a general model for the weight synthesis in a hierarchical structure where $\mathrm{w}_{\mathrm{ij}}$ are local weights of $\mathrm{i}$ element on a given level with relation to the $j$ element from previous level of hierarchical structure, $\mathrm{w}_{\mathrm{j}}$ are weights of elements of previous levels of hierarchical structure and $u_{i}$ is a global element weight in terms of all elements of the previous hierarchical structure levels. Method of ANP (Analytic Network Process) is a network generalization of AHP method (Analytic Hierarchy Process). Analytic network process (ANP) is a method that allows the system to include all possible interdependencies and feedbacks [23]. Strategic partnership of the chain units can be modeled using network structures. The structure of the ANP model is suitable for expressing dependencies within the network of supply / distribution relationships, where units of supply / distribution chains can be grouped into so-called clusters and linked by streams affect-

Table 2. Experimentally derived RI values [22]

\begin{tabular}{|c|c|c|c|c|c|c|c|c|c|c|c|c|c|c|c|}
\hline Rank & $\mathbf{1}$ & $\mathbf{2}$ & $\mathbf{3}$ & $\mathbf{4}$ & $\mathbf{5}$ & $\mathbf{6}$ & $\mathbf{7}$ & $\mathbf{8}$ & $\mathbf{9}$ & $\mathbf{1 0}$ & $\mathbf{1 1}$ & $\mathbf{1 2}$ & $\mathbf{1 3}$ & $\mathbf{1 4}$ & $\mathbf{1 5}$ \\
\hline $\mathrm{RI}$ & 0 & 0 & 0.58 & 0.9 & 1.12 & 1.24 & 1.32 & 1.41 & 1.45 & 1.49 & 1.51 & 1.48 & 1.56 & 1.57 & 1.59 \\
\hline
\end{tabular}


Table 3. Input factors and a set of options for the proposed model

\begin{tabular}{|c|c|c|c|c|}
\hline \multirow{12}{*}{ 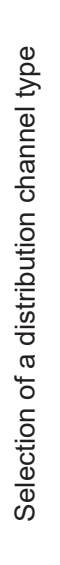 } & \multirow{5}{*}{$\begin{array}{l}\frac{\infty}{0} \\
0 \\
0 \\
\text { U. }\end{array}$} & FC1 - Information & \multirow{12}{*}{ 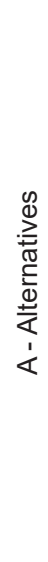 } & \multirow{3}{*}{ A1 - Offtake by the customer } \\
\hline & & FC2 - Storage & & \\
\hline & & FC3 - Operational & & \\
\hline & & FC4 - Boot & & \multirow{3}{*}{ A2 - Direct distribution } \\
\hline & & FC5 - Transport & & \\
\hline & \multirow{7}{*}{ 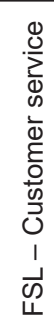 } & FSL1 - Product Availability & & \\
\hline & & FSL2 - Customer satisfaction & & \multirow{3}{*}{$\begin{array}{c}\text { A3 - Local branches or warehouses } \\
\text { / distribution centers }\end{array}$} \\
\hline & & FSL3 - Consolidation of orders & & \\
\hline & & FSL4 - Order tracking & & \\
\hline & & FSL5 - Reliability of supply & & \multirow{3}{*}{ A4 - Cross-dock center } \\
\hline & & FSL6 - Speed of delivery & & \\
\hline & & FSL7 - Reverse logistics & & \\
\hline
\end{tabular}

ing their dependency. These model clusters can represent suppliers, manufacturers, distributors, customers and these links between clusters represent possible influences between elements of different clusters and loops at individual clusters represent possible links between elements of the cluster. For dealing with the network structures using ANP. There is a program available named Super Decisions by CDF company (Creative Decisions Foundation), which will be used in the proposed model.

\section{THE APPLICATION OF THE PROPOSED MODEL}

To determine the most accurate values of pairwise comparison there were three groups of evaluators created. The first group was composed practitioners in the form of logistics manager, purchasing manager, and sales director. The second group consisted of a group of scientists, dealing with logistics, which drew on currently available studies and their own experience. The third group was the professional community, using different types of distribution channels in the form of transporters, customers and end customers.

Determination of input factors and suitable alternatives using a modified Delphi method - A model was designed based on the Delphi method, consisting of input conditions containing costs relevant to the choice of type of the distribution chain and the level of individual services, occurring in the distribution chain. From the perspective of each alternative of distribution channels, four suggested types were assessed by the Table 3 .

Assembling the resulting pairwise comparison matrix by using the Saaty method - From the three resulting matrices obtained from each group of evaluators, the resulting matrix was calculated using the Saaty method. Individual groups were assigned a weight according to the degree of their influence on the final model.

Determination of the linkages and the resulting weights by ANP - To determine the mutual linkages and calculate the resulting weights a Super Decisions program by CDF was used, which is useful in solving problems with multiple interrelated input factors. Solution by using AHP method would be slow and inefficient. The assembled model in the program is shown in Figure 6.

Paired comparison obtained by using the method of Delphi in the step II. was entered into the program to individual evaluation groups and by exporting an unweighted matrix was obtained for each factor. This matrix is shown in Table 4 and 5.

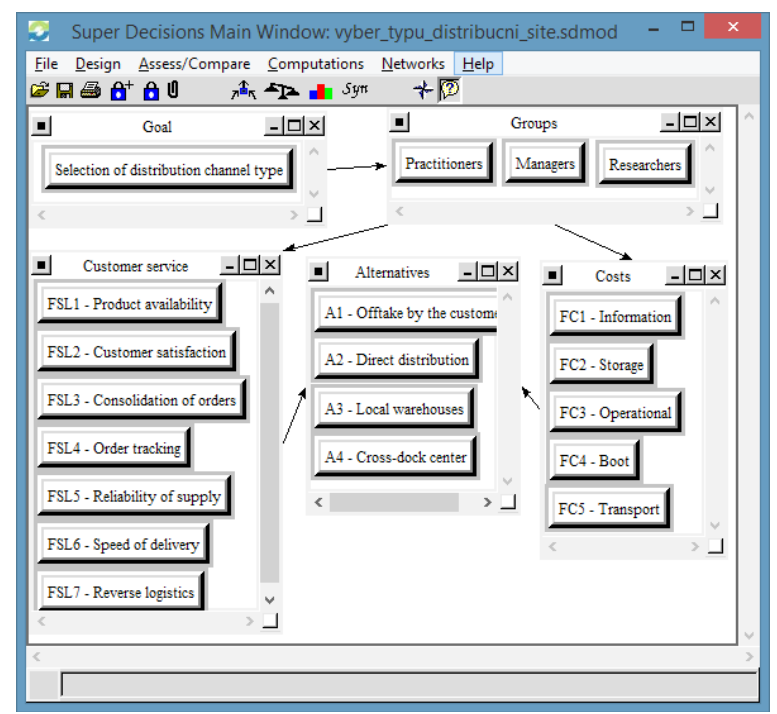

Fig. 6. Proposed ANP model 
Table 4. Unweighted ANP matrix of cost criteria

\begin{tabular}{|c|c|c|c|c|c|}
\hline ANP matrix pro FC & FC1 & FC2 & FC3 & FC4 & FC5 \\
\hline A1 & 0.4587 & 0.0346 & 0.3225 & 0.0473 & 0.4364 \\
\hline A2 & 0.1508 & 0.5475 & 0.4860 & 0.6210 & 0.0857 \\
\hline A3 & 0.3558 & 0.1078 & 0.1094 & 0.0622 & 0.2601 \\
\hline A4 & 0.0348 & 0.3101 & 0.0821 & 0.2694 & 0.2178 \\
\hline
\end{tabular}

Table 5. Unweighted ANP matrix of customer service

\begin{tabular}{|c|c|c|c|c|c|c|c|}
\hline ANP matrix pro FCL & FSL1 & FSL2 & FSL3 & FSL4 & FSL5 & FSL6 & FSL7 \\
\hline A1 & 0.0419 & 0.4177 & 0.2654 & 0.0500 & 0.1768 & 0.5426 & 0.6629 \\
\hline A2 & 0.5329 & 0.0776 & 0.0344 & 0.1800 & 0.0845 & 0.0401 & 0.0449 \\
\hline A3 & 0.0608 & 0.1746 & 0.1821 & 0.0858 & 0.2754 & 0.3352 & 0.2270 \\
\hline A4 & 0.3643 & 0.3301 & 0.5180 & 0.6842 & 0.4634 & 0.0821 & 0.0652 \\
\hline
\end{tabular}

Table 6. The result of the ANP method

\begin{tabular}{|c|c|c|c|}
\hline Name & Ideals & Normals & Raw \\
\hline A1 - Offtake by the customer & 0.864610 & 0.277077 & 0.092359 \\
\hline A2 - Direct distribution & 0.689286 & 0.220892 & 0.073631 \\
\hline A3 - Local warehouses & 0.566574 & 0.181567 & 0.060522 \\
\hline A4 - Cross-dock center & 1.000000 & 0.320465 & 0.106822 \\
\hline
\end{tabular}

In conclusion, we calculate the proposed model using an ANP method. The results are shown in Table 6.

The results are clear. The best option for the proposed issue is set up a distribution channel with one cross-dock center or warehouse placed on the targeting market. The results have been counted with an APN method and 3 different values have been shown. Column Ideals (ideal variants) shows a variant with the higher weight as an ideal variant and the others are its shares.
These results are used for comparing values between each other. Normals (normalized variants) shows weights normalized in an exact way then their sum is equal to 1 . These values we can see in the AHP method. Raw (gross variants) is a vector acquired directly from the limited super matrix. These values are useful for future counting. The Table 6 is graphically illustrated in Figure 7.

The model results clearly show that the current model in the form of local branches is the least appropriate one. Introducing distribution

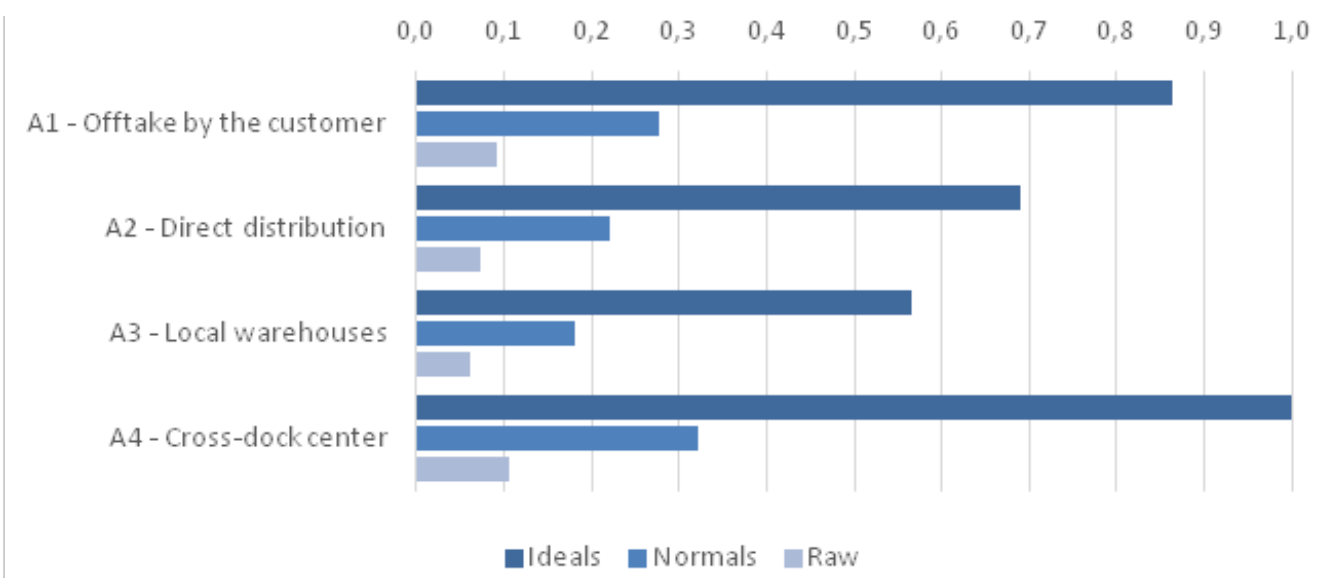

Fig. 7. Graph of the results of the ANP method 
channel in the form of the cross-dock center for the company is preferable from the viewpoint of the level of customer service and of the significant reduction of costs, which is shown primarily by eliminating losses in the distribution channel. The company cannot afford the complete abolition of local branches due to a local dealership, so the reduction will be implemented in local warehouses, which will result in sufficient cost reductions.

\section{CONCLUSION AND FINAL DISCUSSION}

Appropriate choice of the type of distribution channel can save the enterprise considerable amount of financial resources. This article focused on designing and building a model for selection of a suitable type of distribution channel, mainly for to the expenses reduction of the existing distribution channel and simultaneously for assessment of its suitability for the company.

The proposed model provides a clear insight on the discussed issues of selecting the type of distribution channel for the company's management while considering various input factors, with the possibility to modify these factors within the proposed model. The model is formed by modified version of Delphi method and also the method of ANP. The Delphi method is in this case based on pairwise comparison of input factors and then their influence on the type of distribution routes. The ANP method takes into account different preferences between criteria and a wide range scoring scale. The presented model is able to work with both qualitative and quantitative criteria.

Despite the quality and clarity of the proposed model, the greatest threat to the accuracy and relevance of the model is the input formation of pair evaluation. This evaluation may have a profound impact on the outcome of the model and even at small inconsistency level of input evaluation, the outcome may be affected. In the presented model, this is prevented by setting up three major evaluation teams of more members which ensure removal of fluctuations or inconsistency of evaluation. For each pair evaluation, there is also a consistency analysis which immediately warns you about any evaluation discrepancy.

\section{ACKNOWLEDGEMENTS}

This contribution is the result of the projects VEGA 1/0403/18, VEGA 1/0063/16, VEGA 1/0708/16, KEGA 018TUKE-4/2016.
The authors would like to thank everyone who participated in this research for their valuable suggestions, comments, and ratings. Big thanks also go to all employees of the discussed company for their patience and willingness during the input evaluation processing for the model creation. The work was created in connection with the scientific research project of the University of Pardubice no. 51030/20/SG550001.

\section{REFERENCES}

1. Agarwal P., Sahai M., Mishra V., Bag M. and Singh $\mathrm{V}$. A review of multi-criteria decision-making techniques for supplier evaluation and selection. International journal of industrial engineering computation, 2(4), 2011, 801-810.

2. Alias M.A, Hashim M., Zaiton S. and Samsudin S. Multi-criteria decision making and its applications: a literature review. Jurnal Teknologi Maklumat, 20(2), 2008, 129-152.

3. Aruldoss M., Lakshmi T.M. and Venkatesan V.P. A survey of multi-criteria decision-making methods and its applications. American Journal of Information Systems, 1(1), 2013, 31-43.

4. Bernroider E.W. and Mitlohner J. Characteristics of the multiple attribute decision-making methodology in enterprise resource planning software decisions. Communications of the IIMA, 5(1), 2015, 1-6.

5. Costantino F., Di Gravio G. and Shaban A. Multicriteria logistics distribution network design for mass customization. International Journal of Applied Decision Sciences, 7(2), 2014, 151-167.

6. Gašparík J. Definovanie predajných kanálov železničného podniku. Perner's Contacts, 2006, 3-9.

7. Ho W. and Emrouznejad A. Multi-criteria logistics distribution network design using SAS/OR. Expert Systems with Applications, 36(3), 2009, 7288-7298.

8. Ho W., Xu X. and Dey P.K. Multi-criteria decision making approaches for supplier evaluation and selection: A literature review. European Journal of Operational Research, 202(1), 2010, 16-24.

9. Chan F.T.S., Chan H.K., Lau H.C.W. and Ip R.W.L. An AHP approach in benchmarking logistics performance of the postal industry. Benchmarking: An International Journal, 13(6), 2006, 636-661.

10. Isıklar G. and Buyukozkan G. Using a multi-criteria decision-making approach to evaluate mobile phone alternatives. Computer Standards \& Interfaces, 29, 2007, 265-274.

11. Isıklar G., Alptekin E. and Buyukozkan G. Application of a hybrid intelligent decision support model in logistics outsourcing. Computers \& Operation Research, 34, 2007, 3701-3714. 
12. Kahraman C., Cebeci U. and Ulukan Z. Multi-criteria supplier selection using fuzzy AHP. Logistics Information Management, 16(6), 2003, 382-394.

13. Kunz J. Complexity of performance measures and decision quality. International Journal of Applied Decision Sciences, 3(4), 2010, 331-337.

14. Linstone H.A. and Turoff M. The Delphi method: Techniques and applications, Vol. 29. Reading, MA: Addison-Wesley, 1975.

15. Lu J., Zhang G. and Ruan D. Multi-objective group decision making: methods, software, and applications with fuzzy set techniques. Imperial College Press, 2007.

16. Mallen B. Selecting channels of distribution: a multi-stage process. International Journal of Physical Distribution \& Logistics Management, 26(5), 1996, 5-21.

17. Nilay Serbest G. and Vayvay O. Selection of the most suitable distribution channel using fuzzy Analytic Hierarchy Process in Turkey. International Journal of Logistics Systems and Management, 4(5), 2008, 487-505.

18. Onut S. and Soner S. Transshipment site selection using the AHP and TOPSIS approaches under fuzzy environment. Waste Management, 28, 2007, $1552-1559$

19. Qureshi M.N., Kumar P. and Kumar D. Selection of Transportation Company: An analytic network process (ANP) approach, 2013.

20. Rao R.V. Introduction to Multiple Attribute Decision-making (MADM) Methods. Decision Making in the Manufacturing Environment: Using Graph
Theory and Fuzzy Multiple Attribute Decision Making Methods, 27-41.

21. Weiszer M., Fedorko G. and Molnar V. Bi-objective optimization of timetabling and vehicle scheduling in public transportation. Proc. of Carpathian Logistics Congress (CLC), Cracow, Poland 2013, 330-335.

22. Saaty T.L. The Analytic Hierarchy Process, 3rd ed. McGraw-Hill, New York, NY, 1980.

23. Saaty T.L. How to make a decision: the analytic hierarchy process. Interfaces, 24(6), 1994, 19-43.

24. Selçuk P. Evaluation of third-party logistics (3PL) providers by using a two-phase AHP and TOPSIS methodology. Benchmarking: An International Journal, 16(5), 2009, 588- 604.

25. Sha D.Y. and Che Z.H. Supply chain network design: partner selection and production/distribution planning using a systematic model. Journal of the Operational Research Society, 57(1), 2006, 52-62.

26. Singh A. and Malik S.K. Major MCDM Techniques and their application-A Review. IOSR Journal of Engineering, 4(5), 2014, 15-25.

27. Wu C.R., Lin C.T. and Lin Y.F. Selecting the preferable bank assurance alliance strategic by using expert group decision technique. Expert Systems with Applications, 36(2), 2009, 3623-3629.

28. Zylstra K.D. Lean distribution: applying lean manufacturing to distribution, logistics, and supply chain. John Wiley \& Sons, 2012.

29. Sabadka D., Molnar V., Fedorko G. and Jachowicz T. Optimization of Production Processes Using the Yamazumi Method. Advances in Science and Technology Research Journal, 11(4), 2017, 175-182. 